\title{
Evaluation of Magnetic Meters for Irrigation Pipeline Measurement
}

\author{
Stuart W. Styles ${ }^{1}$ and Bryan Busch ${ }^{2}$ \\ ${ }^{1}$ Assoc. Professor, Cal Poly State University BioResource and Agricultural Engineering Dept. and Director, \\ Irrigation Training and Research Center. Phone: (805) 756-2429. Fax: (805) 756-2434. sstyles@calpoly.edu \\ ${ }^{2}$ Irrigation Support Engineer, Cal Poly ITRC. Phone: (805) 756-2434. Fax: (805) 756-2434. \\ bbusch@calpoly.edu
}

\begin{abstract}
Magnetic flow meters are used to measure the flow rate of a liquid in a closed pipeline. This type of meter is becoming increasingly popular for measurement with agriculture applications. Electromagnetic meters were tested by the Irrigation Training and Research Center in pipelines located less than the 10 diameters upstream of disturbances with good results. Results show that location guidelines for placing a magnetic meter can be decreased even for turbulent conditions. This paper will discuss how a magnetic flow meter works, advantages and disadvantages of this type of meter, test results, and new guidelines for field applications.
\end{abstract}

\section{INTRODUCTION}

The accuracy and long-term success of any flow measurement program depends on many factors. Magnetic flow measurement is rapidly becoming the technique of choice in pipelines because of its simplicity and accuracy. However, the application of this technology has been limited in the past because of standard practice guidelines for magnetic flow meters, which have required installing the meters in a straight section of pipe at least 8-10 pipe diameters from any source of turbulence. In addition, standard practice recommends having at least two pipe diameters of straight unobstructed pipe downstream from the meter. However, in the case of many irrigation pumping plants, turnouts, and deliveries, these conditions can rarely be met without extensive and expensive modifications. Therefore, the Irrigation Training and Research Center (ITRC) at Cal Poly State University San Luis Obispo is currently investigating electromagnetic flow meters for potential applications under non-standard conditions.

Several current manufacturers claim that their magnetic meters can perform well even in locations where only two diameter lengths of straight pipe are available. Testing was done by the ITRC on several magnetic meters at the Cal Poly Water Resources Facility to evaluate comments by the manufacturers and to make recommendations to irrigation districts and growers interested in this new technology.

This research was conducted to determine:

- The accuracy of the magnetic meters in locations that are less than optimal

- The sensitivity of meters to increasing amounts of turbulence

Since this research was conducted, there have been numerous field installations of magnetic meters in various irrigation applications in California. The general consensus is that they are working well. 


\section{Magnetic Meters}

According to Faraday's Law, a voltage will be induced proportional to the velocity of a conductor as it moves at right angles through a magnetic field. The water in the pipe is the conductor. By simply measuring the voltage, a magnetic meter is able to calculate the volume of the liquid passing through a controlled section.

$$
\begin{aligned}
& \text { Faraday's Formula: } \quad \mathbf{E} \text { is proportional to } \mathbf{V} \times \mathbf{B} \times \mathbf{D} \\
& \qquad \begin{aligned}
\mathbf{E} & =\text { The voltage generated in a conductor } \\
\mathbf{V} & =\text { The velocity of the conductor } \\
\mathbf{B} & =\text { The magnetic field strength } \\
\mathbf{D} & =\text { The length of the conductor }
\end{aligned}
\end{aligned}
$$

This principle works for irrigation water passing through the magnetic field generated by the magnetic meter since the water acts as the conductor. The basic operating principle for magnetic meters is illustrated in Figure 1. Note that this discussion is limited to full-bore or in-line magnetic meters. There are several other types of meters on the market but this type is the one that was evaluated.

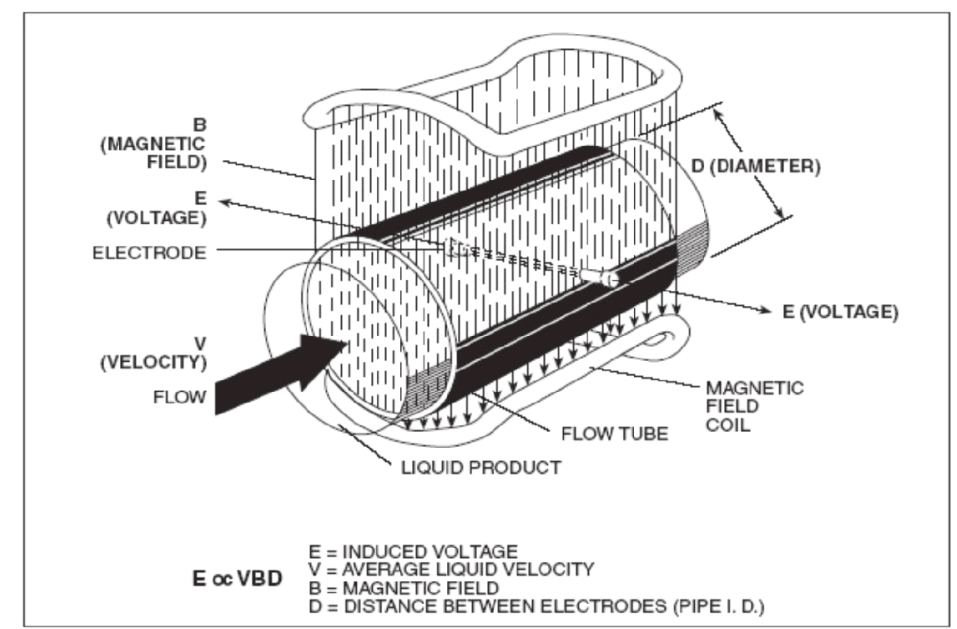

Figure 1. Operating principle for full-bore magnetic meter (Omega 2009)

As seen in Figure 2, there are two electrodes located inside the magnetic meter to measure the induced voltage. The flow rate/totalizer indicator is located on the top of the unit. These units can be placed at any angle. It is recommended that they be rotated so that one of the electrodes does not sit on the bottom of the pipe. This helps prevent problems from sediment covering the electrode. Note that on the unit in Figure 2, the magnetic field is generated by an insert unit into the pipeline. Some manufacturers install the coils to generate the magnetic field outside of the spool piece. 


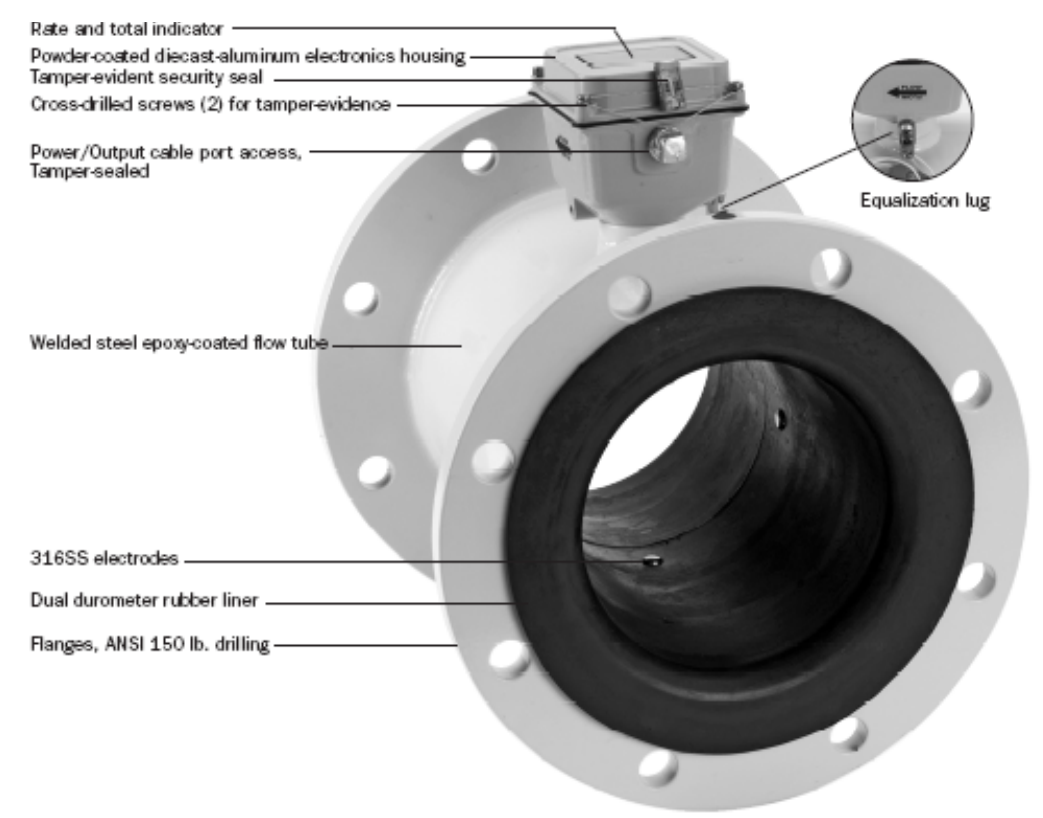

Figure 2. View of typical magnetic meter (SeaMetrics 2009)

\section{$\underline{\text { Advantages of Magnetic Meters }}$}

- Highly accurate even with some flow disturbance.

- No headloss caused by meter.

- Is not impacted by trash, sediment, or sand.

- Can measure a wide range of velocity. This is a key criterion in areas that have seasonal high flows combined with very low flows.

- Has instantaneous and volumetric totalizing capability.

- Measurement accuracy is NOT affected by varying canal water levels.

- Minimal maintenance required.

- Temperature of the liquid has no effect on accuracy.

Disadvantages of Magnetic Meters

- Cost is a major constraint. Recently the cost has dropped dramatically, but this is still the most expensive option in some cases.

- $\quad$ Pipe must be full (as is the case in most agricultural applications).

- Installation into existing sites is often difficult and expensive.

- Sensitivity to turbulence.

\section{Turbulence and Magnetic Meters}

Magnetic meters have been considered particularly tricky for pumping plants and turnouts, because of the meter's sensitivity to turbulence. For example, one of the main problems associated with turnouts is the turbulence that occurs just downstream of the gate. Figure 3 shows a typical turnout application with a magnetic meter. 


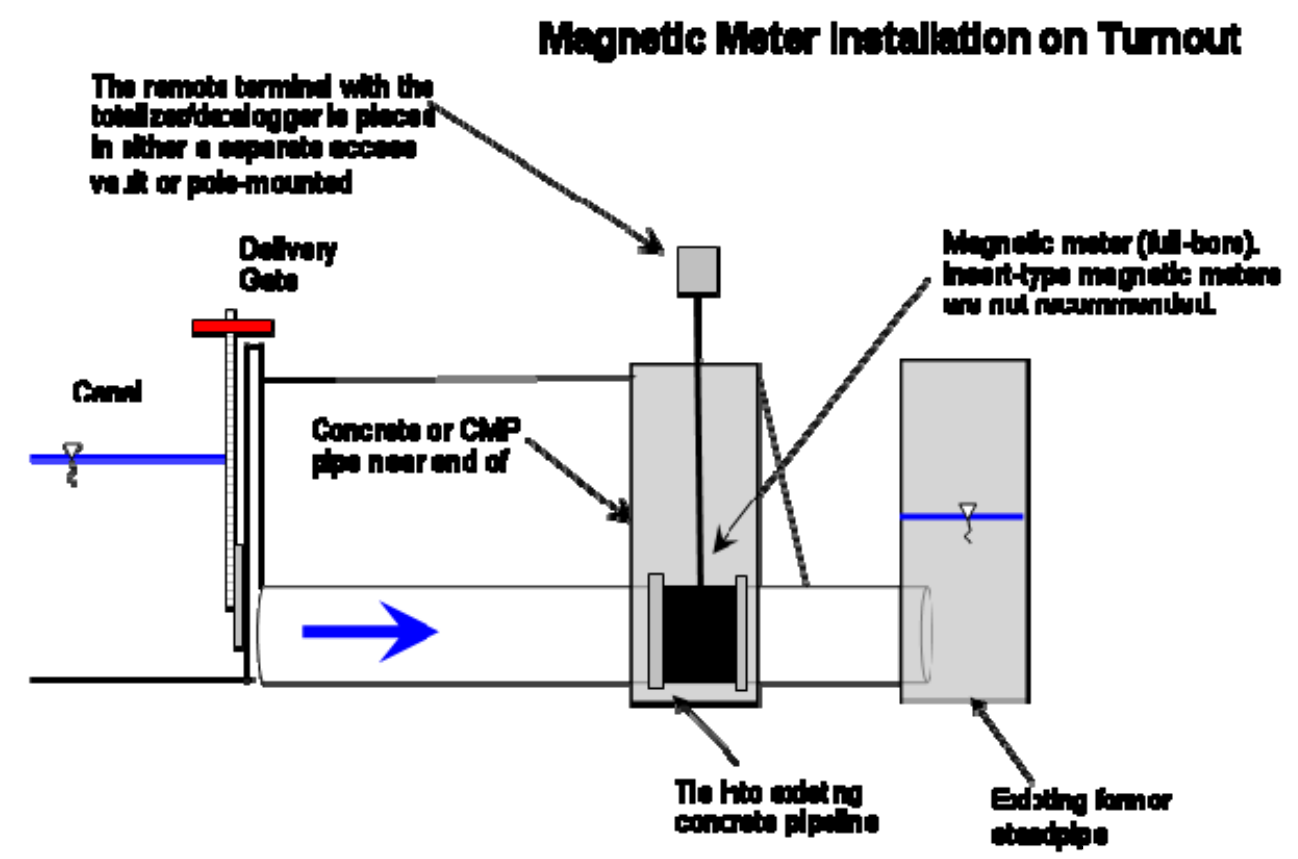

Figure 3. Conceptual sketch of magnetic meter installation for turnouts (not to scale)

In 1998, Hanson and Schwankl published results from non-optimal flow meter testing in their paper Error Analysis of Flowmeter Measurements. Pipeline measurements were taken with different types of flow meters to determine the effects on error resulting from different degrees of turbulence caused by elbows, check valves, and a partially opened check valve. Measurements were made at 2, 5, 10, and 15 pipe diameters downstream from the source of turbulence.

The results from Hanson and Schwankl (1998) indicated that for generally acceptable accuracy with propeller meters, pitot meters, and Doppler meters, measurements should be taken upstream of valves. The tests found that in some circumstances even with as little as 2 or 5 pipe diameters upstream of a flow meter, there were still large errors with all meters under conditions of severe turbulence.

Since most applications require the flow measurement downstream of a valve or turnout gate, manufacturers have recently claimed that their magnetic flow meter technology is now able to work effectively in situations where there is as little as two diameters of pipe length available. ITRC tested several magnetic meters at the Cal Poly Water Resources Facility to investigate these claims.

\section{METHODOLOGY}

Several manufacturers were tested in this study. The results are included here for one of the manufacturers $^{1}$. Flow rates for the testing were measured with the SeaMetrics AG2000

\footnotetext{
${ }^{1}$ Reference to any specific product does not imply an endorsement or recommendation of use by the authors. The products names are included for completeness and clarifications in this paper.
} 
Irrigation Magmeter in two different configurations at the Cal Poly Water Resources Facility. Two tests were conducted over a flow range of approximately 0.8 to 115 lps (12 to 1,800 gpm) using a second magnetic meter in optimal flow conditions as the control unit. Figure 4 depicts the facilities used for testing.

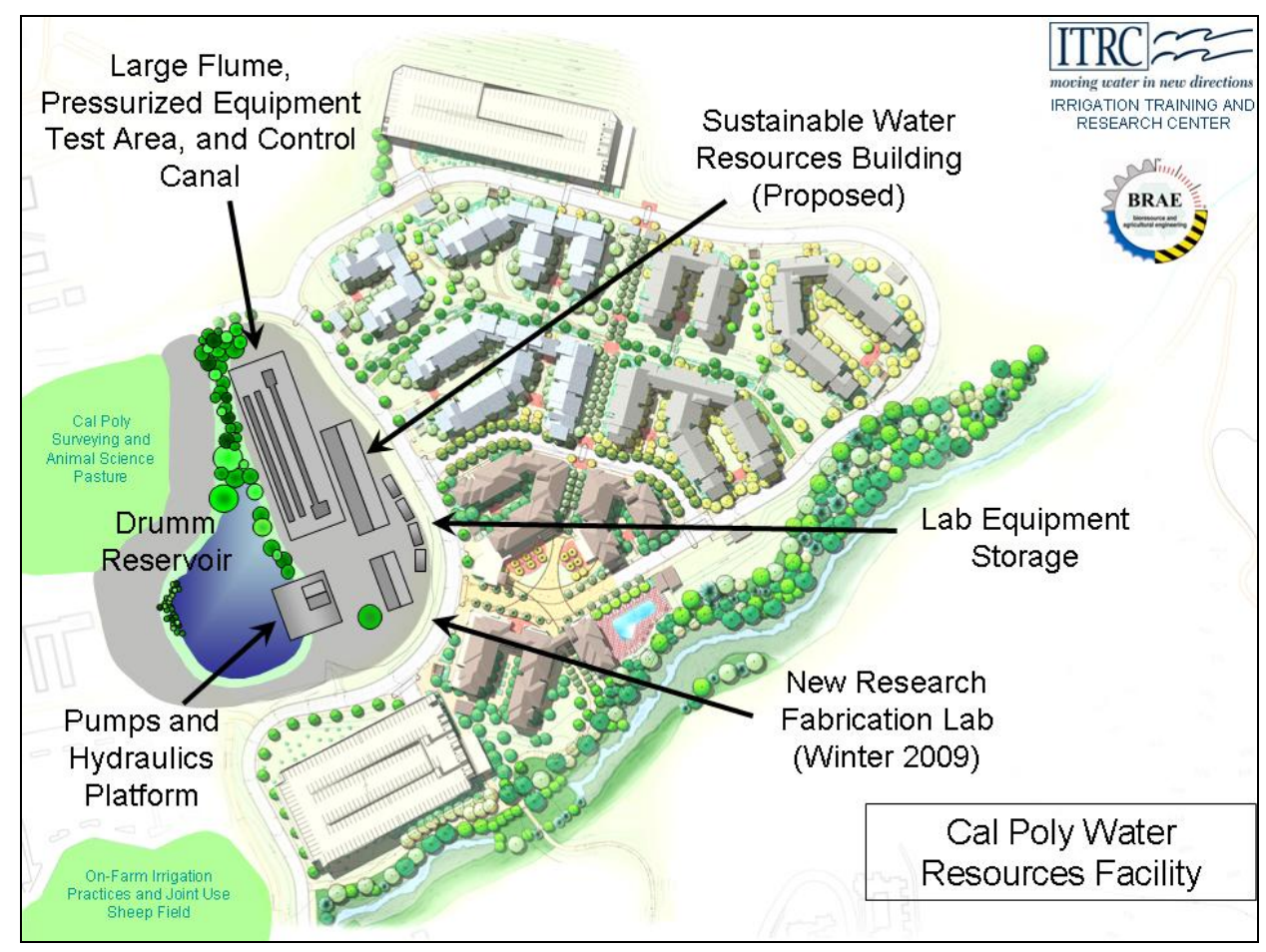

Figure 4. Cal Poly Water Resources Facility

The AG2000 flow meter readings were compared with the control unit to calculate the percent error in this paper as follows:

$$
\% \text { Error }=\frac{\text { AG2000 flow meter }- \text { Control unit }}{\text { Control unit }} \times 100
$$

The AG2000 flow meter is an electromagnetic flow meter for use in 10 to $30 \mathrm{~cm}$ (4 to 12 inch) diameter pipelines. An optional 4-20 mA output module (AO55W) is available for remote monitoring applications with Supervisory Control and Data Acquisition Systems (SCADA) systems. The standard unit is battery powered and optional configurations are available for use with an external power source.

The control units used for the tests were a $10 \mathrm{~cm}$ (4 inch) and $30.5 \mathrm{~cm}$ (12 inch) McCrometer Ultra Mag flow meter, which had been calibrated using the weighing tank facility at the Water Resources Facility. ITRC did not attempt to verify the true accuracy of the AG2000 flow meter readings, only the percent error from the control units.

A magnetic flow meter was mounted on the Water Resources Facility Pump \#2, downstream of a cast-iron concentric reducer, and immediately downstream of a butterfly valve (refer to Figure 5), designated as Test \#1. The retail cost of this $25.4 \mathrm{~cm}$ (10 inch) magnetic meter is 
$\$ 1,485$, which is comparable to a standard propeller meter. This test configuration was designed to represent the "worst possible conditions imaginable" in an actual irrigation application.

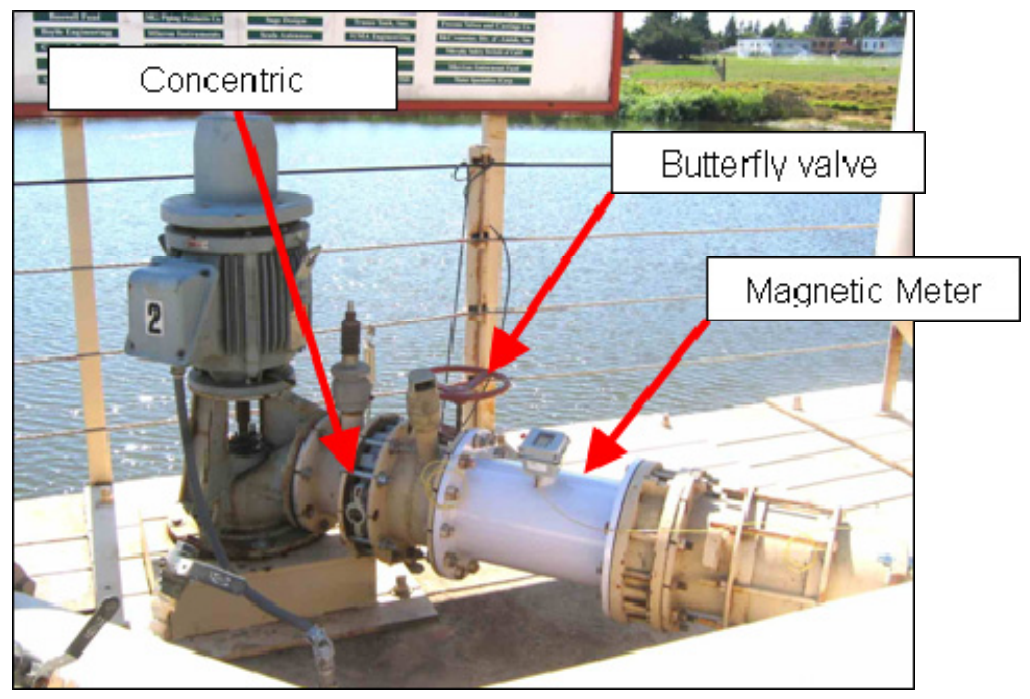

Figure 5. AG2000 test condition for Test \#1 (10-inch)

A second AG2000 flow meter was mounted in a straight section of $10 \mathrm{~cm}$ (4 inch) pipeline only 20 centimeters ( 8 inches) downstream from a butterfly valve (equivalent to 2 pipe diameters), designated as Test \#2 (see Figure 6). The retail cost of this $10 \mathrm{~cm}$ (4 inch) magnetic meter is $\$ 990$, which is comparable to a standard propeller meter.

Once the initial flow rate was established, turbulence was introduced into the pipeline. The butterfly valves were adjusted during the tests from wide open to $75 \%$ and $90 \%$ closed in Tests \#1 and \#2, respectively. This testing would represent the worst possible case for irrigation applications.

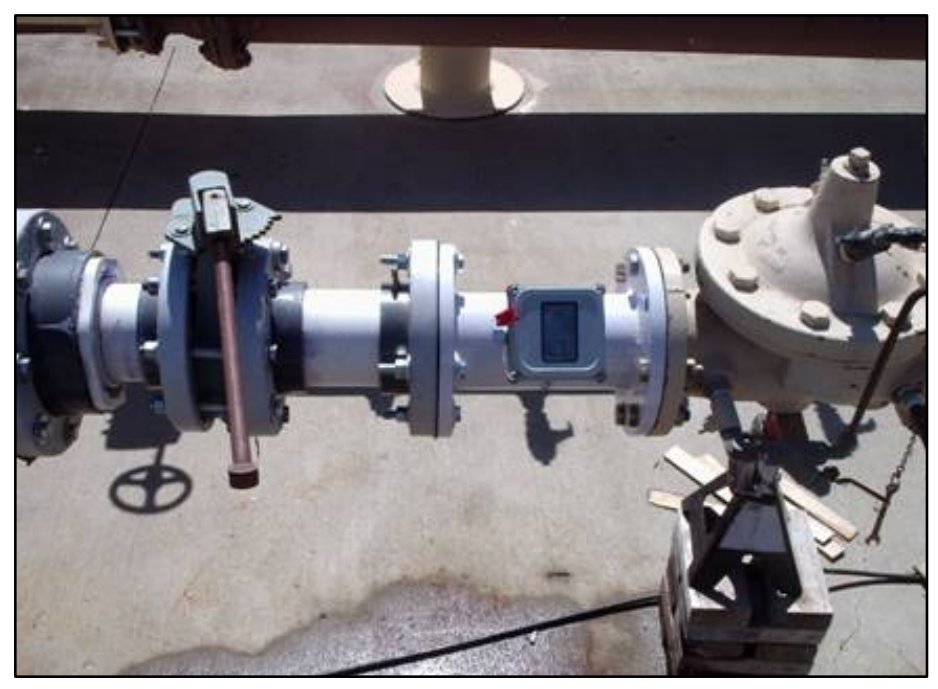

Figure 6. AG 2000 test configuration for Test \#2 (2 dia u/s \& 0 dia d/s) 


\section{RESULTS}

The error analysis of the AG2000 flow meter test results is summarized in Table 1. In Test $\# 1$, the percent error was less than $\underline{\mathbf{+ 2 \%}}$ when the butterfly valve was partially closed up to $50 \%$. The percent error was more than $-10 \%$ when the butterfly valve was closed more than $75 \%$. This increase in percent error may be attributed to the jetting effect of the cast-iron concentric reducer coupled immediately upstream of the butterfly valve.

Errors for this meter increased as the valve was closed and the flow rate was reduced. The AG2000 flow meter had a positive percent error (overestimating the flow rate) compared to the control unit when the butterfly valve was closed $50 \%$ or less. When the butterfly valve was closed more than 50\% the AG2000 flow meter underestimated the flow rate by approximately $6-12 \%$.

By comparison, the results reported by Hanson and Schwankl (1998) for partially closed butterfly valves with a propeller meter mounted two diameters downstream were $\pm 14 \%$ at $42.7 \mathrm{lps}(668 \mathrm{gpm}), \pm 15 \%$ at $73.7 \mathrm{lps}(1,153 \mathrm{gpm})$, and $\pm 2 \%$ for flow rates of $139.9 \mathrm{lps}$ (2,190 gpm). The valve was closed 10 degrees (out of 90 degrees) to provide the throttling effect. Based on the results of their study, it was recommended to always use a six vane straightening arrangement if measuring the flow rate downstream of a throttled butterfly valve.

The test results indicate that the AG2000 Irrigation Magmeter can be installed downstream of partially closed butterfly valves or other sources of turbulence without excessively degrading accuracy.

Table 1. AG2000 Test Results at Cal Poly ITRC Water Resources Facility

\begin{tabular}{|c|c|c|c|c|c|c|}
\hline Test \# & Valve Position & $\begin{array}{c}\text { Ultra Mag } \\
\text { Flow Rate } \\
\text { (lps) }\end{array}$ & $\begin{array}{c}\text { Ultra Mag } \\
\text { Flow Rate } \\
(\text { gpm })\end{array}$ & $\begin{array}{c}\text { AG2000 } \\
\text { Flow Rate } \\
\text { (lps) }\end{array}$ & $\begin{array}{c}\text { AG2000 } \\
\text { Flow Rate } \\
\text { (gpm) }\end{array}$ & $\begin{array}{c}\text { Error } \\
(\%) \\
\end{array}$ \\
\hline \multirow{5}{*}{$\begin{array}{c}\text { Test \#1 } \\
25.4 \mathrm{~cm} \\
\left(10^{\prime \prime}\right) \\
\text { meter }\end{array}$} & Open & 114.4 & 1,791 & 116.0 & 1,816 & +1.4 \\
\hline & $50 \%$ closed & 102.1 & 1,597 & 102.4 & 1,603 & +0.4 \\
\hline & $60 \%$ closed & 90.4 & 1,414 & 88.4 & 1,383 & -2.2 \\
\hline & $70 \%$ closed & 81.2 & 1,271 & 72.8 & 1,140 & -6.3 \\
\hline & $75 \%$ closed & 63.4 & 992 & 55.5 & 868 & -12.5 \\
\hline \multirow{5}{*}{$\begin{array}{c}\text { Test \#2 } \\
10 \mathrm{~cm} \\
\left(4^{\prime \prime}\right) \\
\text { meter }\end{array}$} & Onen & 256 & 401 & 256 & 401 & 0 \\
\hline & $50 \%$ closed & 21.6 & $\frac{401}{338}$ & $\frac{25.0}{21.6}$ & $\begin{array}{l}401 \\
338\end{array}$ & $\frac{0.0}{0.0}$ \\
\hline & $70 \%$ closed & 7.9 & 124 & 7.9 & 123 & -0.8 \\
\hline & $80 \%$ closed & 2.0 & 31 & 2.0 & 31 & 0.0 \\
\hline & $\approx 90 \%$ closed & 0.8 & 12 & 0.8 & 12 & 0.0 \\
\hline
\end{tabular}

In Test \#2, the $10 \mathrm{~cm}$ (4 inch) AG2000 flow meter had a percent error of less than $1 \%$ even when the butterfly valve was $90 \%$ closed. Discrepancies were the same for conditions where the butterfly valve was wide open and when it was closed $80-90 \%$. These results suggest that turbulence from a partially closed butterfly valve located two pipe diameters upstream had a negligible effect on the precision of the magnetic meter as compared to the control unit. 
In summary, the test results indicated that under conditions of severe turbulence due to a partially closed butterfly valve, the $10 \mathrm{~cm}$ (4 inch) AG2000 flow meter readings were not adversely affected. For the $24.4 \mathrm{~cm}$ (10 inch) AG2000 flow meter, a partially closed butterfly valve coupled with a pump discharge caused errors of $1-2 \%$ up to $50 \%$ valve closure. The recorded percent error was generally reduced at the higher flow rates.

\section{CONCLUSION}

The test results indicate that the magnetic meter tested can be installed downstream of partially closed butterfly valves or other sources of turbulence without excessively degrading accuracy. Additionally, the magnetic meter is able to provide accurate readings to within $\pm 2 \%$, which is well within the limits expected for agricultural delivery. The costs of these units have also decreased to the point where they are competitive with traditional devices that cannot handle the turbulence associated with some irrigation applications.

\section{REFERENCES}

Hanson, B.R., and Schwank1, L.J. 1998. "Error Analysis of Flowmeter Measurements." J. Irrig. and Drain. Engr., ASCE 124(5), 248-256.

SeaMetrics, Inc. 2009. "Instructions: AG2000 Irrigation Magmeter." http://www.seametrics.com/flow meter/agAG.html

OMEGA. 2009. Engineering Technical Reference, "Introduction to Magnetic Flow Meters." http://www.omega.com/prodinfo/magmeter.html 